\title{
Harinas y almidones de yuca, ñame, camote y ñampí: propiedades funcionales y posibles aplicaciones en la industria alimentaria.
}

Cassava, yam, sweet potato and ñampi starch: functional
properties and possible applications in the food industry.

Pedro Vargas Aguilar'

Diana Hernández Villalobos²

Fecha de recepción: 22 de febrero del 2012

Fecha de aprobación: 25 de octubre del 2012

Vargas, P; Hernández, D. Harinas y almidones de yuca, ñame, camote y ñampí: propiedades funcionales y posibles aplicaciones en la industria alimentaria. Tecnología en Marcha. Vol. 26, № I Pág

37-45 


\section{Palabras clave}

Tubérculos, almidón, harina, yuca, ñame, ñampí, camote, propiedades funcionales.

\section{Resumen}

Se realizó una revisión de las características fisicoquímicas de las harinas y almidones de yuca, ñame, ñampí y camote, tales como el contenido de amilosa-amilopectina, la viscosidad, el valor nutricional y la fibra, con el fin de relacionarlas con sus propiedades funcionales y técnico-funcionales. Se obtuvo una relación entre el contenido de amilosa-amilopectina, viscosidad y contenido de fibra en la digestibilidad de estos almidones y los valores de índice glicémico. Se encontró que es posible introducir modificaciones por medio de la fermentación para mejorar el valor funcional de estos almidones. La fermentación permite elaborar pan sin gluten y bebidas energéticas como nuevas opciones de productos. También se encontró que existe una relación entre la viscosidad de los almidones y la disminución de absorción de la grasa en frituras.

\section{Key words}

Tropical roots, starch, cassava, yam, ñampí, sweet potato, functional properties.

\begin{abstract}
A technical review was conducted to related physical and chemical properties of flours and starches from cassava, yams, taro and sweet potato. Amyloseamylopectin content, viscosity, nutritional value and fiber, were studied to relate them with starch functional properties. A relationship was obtained between amylose-amylopectin, viscosity and fiber content with the digestibility of those starches and the glycemic index values. The use of fermentation to enhance the nutritional value of these starches is known. Starch fermentation allows the production of gluten-free bread and energy drinks as an option to diversify products. It was also observed the relationship between the starch viscosity and the fat absorption in fried foods.
\end{abstract}

\section{Introducción}

El camote (Ipomea batatas), la yuca (Manihot esculenta), el ñame (Dioscorea sp.) y el ñampí (Colocasia esculenta) son productos característicos de la gran franja del trópico y forman parte de la dieta diaria de las personas que viven en estas regiones. A pesar de esto, las nuevas generaciones y las facilidades del comercio actual han llevado a experimentar con nuevos productos, dejando un poco de lado el consumo tradicional de estas raíces. Sin embargo, el valor nutricional, su accesibilidad, así como la versatilidad de los novedosos productos que se obtienen del almidón extraído de estas raíces de origen tropical han llamado la atención de los profesionales del área de los alimentos, que han estudiado las propiedades funcionales de los mismos.

La curiosidad de los científicos por encontrar la forma más natural de mantener la salud de las per- sonas y la diversificación de productos, los ha llevado a estudiar nuevas opciones alimentarias que, por su composición y características, sean beneficiosas para la salud, de forma específica o general, como en el caso de tratamientos preventivos o curativos.

Conocer las propiedades funcionales de los alimentos en general es de suma importancia ya que en el tema de las raíces como camote, ñampí, ñame y yuca aún se encuentran en una etapa inicial, ya que se han investigado en los almidones y harinas de forma aislada, pero han sido pocos los estudios aplicados a los alimentos.

A continuación, se presenta una revisión bibliográfica que recopila estudios relacionados con las propiedades funcionales de los productos mencionados, con el fin de determinar cuáles de ellas se encuentran en estas raíces, así como las posibles aplicaciones en alimentos. 


\section{Desarrollo}

\section{Características fisicoquímicas de las raíces de origen tropical}

\section{Influencia de la relación del contenido de amilosa- amilopectina sobre la digestibilidad del almidón}

Los principales componentes del almidón son la amilosa y la amilopectina. Estos polímeros son muy diferentes en su forma estructural; la amilosa tiene una estructura lineal, mientras que la amilopectina es ramificada. Cada estructura juega un papel importante en la finalidad última del almidón nativo y sus derivados. Industrialmente el rango amilosa/ amilopectina se puede manipular genéticamente, física y químicamente para modificar las características propias como viscosidad, gelatinización, textura, solubilidad, estabilidad del gel y retrogradación, para darle propiedades industriales estables.

El contenido de amilosa también juega un papel importante en la digestibilidad de los alimentos, ya que algunos estudios han determinado que los almidones con un bajo contenido de amilosa son de más fácil digestión que aquellos con un alto contenido (Riley et al., 2006). Por esta razón, se analizará los contenidos de amilosa y amilopectina en los productos tropicales en estudio.

De los estudios que citaremos, se encontró que el contenido de amilosa en el almidón de yuca varía según la especie analizada, y que esa cantidad es afectada por la edad del cultivo o el clima. Lo anterior se puede ver en los resultados obtenidos en el estudio realizado por Onitilo (2007), en África, quien analizó cuatro especies de yuca, en él encontró contenidos de amilosa entre el 20,01\% a 20,47\%; mientras que Moorthy (2004), menciona en su revisión bibliográfica un rango más amplio, que va desde el 20,00\% al 27,00\%, además, indica que de este total de amilosa, aproximadamente el 40\% corresponde a amilosa soluble. Vargas et al. (20 I 2), mencionan que para variedades de yuca cultivadas en Costa Rica (Valencia y Brasileña), los contenidos son del $37 \%$ y $38 \%$ respectivamente. Lo anterior denota la variabilidad en el contendido de amilosa/ amilopectina que pueden tener los mismos productos de diferente origen. Se encontró también, que el contenido de amilopectina en el almidón de yuca según Onitilo et al. (2007), es de 79,53\% a 79,99\%. La variación en los contenidos de amilosa indica que los almidones presentarán propiedades diferentes en los procesos de gelificación.

En cuanto al almidón de camote, Moorthy (2004) encontró un contenido de amilosa de 15,00\%-25,00\%, un rango similar al reportado por Tecson (2007), de 12,90\% a 29,70\%. Osundahusi et al. (2003), hizo un estudio con dos especies de camote (blanco y rojo) procedentes de Nigeria, y reportan un rango mayor a $32,00 \%$ para ambas. Este autor menciona que las diferencias entre estos resultados pueden deberse a que las condiciones de crecimiento (siembra) de la raíz pueden afectar las propiedades físicas de los almidones; y que por ejemplo, si la temperatura del suelo aumenta, la temperatura de gelatinización y el tamaño promedio del gránulo pueden variar (Moorthy, 2004).

Según un estudio realizado por Ting-Jang et al. (2008), el contenido de amilosa en el ñampí es afectado por la especie, al igual que la yuca. Estos autores reportan un rango de amilosa en el ñampí de $10,20 \%$ a $14,90 \%$. En este estudio también se ve el efecto del clima sobre el contenido de amilosa, pues si el cultivo se encuentra a temperaturas más bajas Los contenido de amilosa disminuyen.

El contenido de amilosa en el almidón de ñame presenta variaciones leves de una especie a otra. En promedio, el contenido de amilosa para Discorea alata es de 28,50\%, según Karam et al. (2006), porcentaje muy cercano al reportado por Araujo et al. (2004) para Discoria bulbifera, que mencionan en su estudio un porcentaje de $29,37 \%$ y una cantidad de amilopectina de 70,62\%.

Debido a la variación en el contenido de amilosa entre las especies de un mismo producto, es difícil precisar cuál contiene mayor o menor cantidad de amilosa. Entre los rangos generales, se presenta variaciones en la cantidad de amilosa según la especie de producto. El camote presenta en promedio el valor superior, con $32,00 \%$, seguido por el ñame con $29,00 \%$, la yuca con $27,00 \%$ y el ñampí con $10,20 \%$ a 14,90\%, que son los valores menores.

Si se toma en consideración lo señalado por Riley et al. (2006), en el cual se clasifican los almidones por sus estructuras, se señala que las estructura tipo A son las aquellas que tienen menor contenido de amilosa y mayor contenido de amilopectina, las tipo $B$ un mayor contenido de amilosa y menor contenido de amilopectina y $C$ un contenido intermedio. 
Lo anterior indica que la porción de amilosa en los almidones afecta la digestibilidad. Las estructuras A y $C$ son más digestibles, o sea son más sensibles a la amilasa y la estructura tipo B es menos digerible, o sea menos sensible a la amilasa, y eso según el autor se debe a la estructura cristalina que presenta.

Según un estudio in vitro, es el ñampí el que presentaría una mayor digestibilidad. Sin embargo, Moorthy (2004), quien analizó estudios realizados con animales pequeños, reporta buena digestibilidad para la yuca y el camote y baja para el ñame, mientras que no registró esta variable para el ñampí, por lo cual no es posible determinar para este almidón, si el contenido de amilosa es determinante para la digestibilidad.

A estos productos, aunque generalmente se consideran de fácil digestibilidad, se les asocia con flatulencia, sin embargo, los estudios disponibles no confirman este hecho (Osundahusi et al., 2003).

\section{Viscosidad}

La viscosidad en los alimentos se relaciona con la composición química y la estructura del alimento. Al avanzar el proceso de la gelificación, cambia la composición, estructura y viscosidad del mismo (Robertson, 1988).

En el caso de la yuca, Moorthy (2004) menciona un valor de viscosidad de 600 BU (Unidades Brabender), el cual se considera un valor alto. Por otra parte, el camote presentó un valor menor al de la yuca entre 160 a 450 BU, lo que evidencia la variabilidad en la gelificación que presentan los almidones de diferentes fuentes amiláseas como las estudiadas.

Según Osundahusi et al. (2003), en un gel de almidones de camotes blanco y rojo, la viscosidad baja indica una alta actividad enzimática, resultando en una baja capacidad de retención de agua. En este estudio también se menciona la baja tendencia a la retrogradación de este almidón. En el caso del ñame se mencionan valores "pico de viscosidad" de 781, 756 y hasta 1282 BU (Moorthy, 2004). Las diferencias en los picos de viscosidad se deben también a las estructuras de los almidones.

En cuanto a viscosidad de retrogradación, se presentan valores bajos (-656 a -950 BU), lo que indica baja tendencia a este fenómeno (Rached et al., 2006). En el caso del ñampí no se encontró los datos específi- cos para viscosidad. En las investigaciones indagadas, el ñame obtuvo el valor más alto, seguido por la yuca y el camote con el valor menor, sin embargo, en términos generales se obtuvo valores muy diferentes entre las raíces estudiadas. Robertson (1988), quien en su estudio simula un proceso de digestión, encontró una posible relación entre la digestibilidad y la viscosidad, según la cual entre más viscoso es el alimento más lento es la digestión. Si tomamos en cuenta esto y se relaciona con lo mencionado por Moorthy (2004) respecto a la digestibilidad de los almidones, es posible decir que entre mayor sea la viscosidad, menor digestibilidad se obtendrá del almidón, ya que según este autor la yuca y el camote, los cuales presentan los valores más bajos de viscosidad, tienen buena digestibilidad; mientras que almidones de alta viscosidad darían como resultado una baja digestibilidad, como fue el caso del ñame, el cual obtuvo valores de viscosidad muy altos y cuyo almidón presenta una baja digestibilidad (Moorthy, 2004).

\section{Gelificación}

La temperatura de gelatinización es una característica específica de cada almidón en particular y depende de diversos factores, tales como el tamaño de los gránulos, la relación amilosa/amilopectina y las fuerzas intra e intermoleculares, entre otras. La temperatura de gelatinización es un índice de ordenamiento intragranular y entre mayor sea este valor, mayor será el grado de asociación de las moléculas en el interior del gránulo de almidón (Rached et al., 2006).

El almidón de yuca tiene una temperatura de gelatinización relativamente baja en comparación con otros almidones, la cual varía de 49 a $64{ }^{\circ} \mathrm{C}$ ó de 62 a $73^{\circ} \mathrm{C}$ (Moorthy, 2004), según la variedad, constitución genética y el ambiente de desarrollo del cultivo. El rango de temperatura de gelatinización dado por Moorthy (2004) para este producto, concuerda con la temperatura reportada por Karam et al. (2006), de $62{ }^{\circ} \mathrm{C}$.

En relación al almidón de ñame, en el estudio realizado por Araujo et al. (2004) en Venezuela, se encontró que la temperatura de gelatinización para este producto es de $70,8{ }^{\circ} \mathrm{C}$, mientras que Rached et al. (2006) encontarron una de $75^{\circ} \mathrm{C}$ y $80{ }^{\circ} \mathrm{C}$ par el mismo producto; ambos estudios presentan similitudes con el realizado por Riley et al. (2006), 
donde se comparó ñames de diferentes fuentes y el rango de temperatura de gelatinización entre 74 a $75^{\circ} \mathrm{C}$. Con esta información, se puede decir que en general, independiente del origen del tubérculo, la temperatura de gelatinización varía y que ésta variación puede darse por el desarrollo del producto que debe de estar influenciado por factores agroclimáticos y de fertilización tal y como lo menciona Treche (1996).

Otro producto evaluado fue el almidón de camote y el estudió demostró que en las dos variedades analizadas, un amplio rango de variación de la temperatura de gelificación que va desde los 63 hasta los $74{ }^{\circ} \mathrm{C}$, según Osundahusi et al. (2003).

En general podemos decir que los almidones nativos, provenientes de diferentes lugares poseen características de gelificación diferentes, y que a veces el rango de temperatura de gelificación varía de manera considerable.

\section{Valor nutricional}

Los tubérculos y raíces son una de las principales fuentes de carbohidratos en la alimentación mundial, sin obviar que en su composición hay otros nutrientes presentes como lo muestra el cuadro I., por lo tanto, la riqueza energética de estos productos se debe principalmente al aporte calórico de los carbohidratos, principalmente del almidón.

En cuanto al contenido energético, se observa en el cuadro I, que éstos productos son una buena fuente calórica; la yuca con un contenido en carbohidratos del $86,9 \%$ base seca, es que provee un mayor aporte calórico en Kcal/l 00 g b.s.

\section{Fibra e índice glicémico}

En el estudio realizado por Tecson en el 2007, se señala la importancia de la fibra sobre la salud y su relación con la mejora del proceso digestivo, igualmente sobre la importancia que tiene ésta en el tratamiento de enfermedades tales como la diabetes, por su influencia positiva sobre el índice glicémico.

El cuadro 2, muestra el estudio que realizó Tecson en el 2007, en el cual utilizó harinas de ñame, camote, yuca y ñampí, en el cual se muestra la variación en los resultados obtenidos tanto en relación al contenido de fibra así como a la respuesta obtenida de índice glicémico. El índice glicémico corresponde

Cuadro I. Contenido calórico de algunos almidones de origen tropical*

\begin{tabular}{|c|c|c|c|c|c|c|}
\hline $\begin{array}{c}\text { Raíz o } \\
\text { Tubérculo }\end{array}$ & $\begin{array}{c}\text { Materia seca }(\mathrm{g} / \mathrm{I00} \mathrm{g} \\
\text { de producto fresco) }\end{array}$ & Proteína & Grasa & $\begin{array}{c}\text { Carbohidratos } \\
\text { totales }\end{array}$ & $\begin{array}{c}\text { Fibra } \\
\text { total }\end{array}$ & Energía (Kcal) \\
\hline Yuca & 31,3 & & \multicolumn{5}{c|}{ / $100 \mathrm{~g}$ base seca } \\
\hline Papas & 22,2 & 2,7 & 0,62 & 86,9 & 7,9 & 364 \\
\hline Camote & 30,8 & 9,2 & 0,50 & 66,7 & 9,3 & 316 \\
\hline Name & 31,1 & 6,3 & 1,95 & 78,2 & 10,2 & 351 \\
\hline
\end{tabular}

*Treche, 1996

Cuadro 2. Contenido de fibra dietética e índice glicémico de algunas raíces de origen tropical*

\begin{tabular}{|c|c|c|c|c|c|}
\hline Ejemplo & \multicolumn{3}{|c|}{ Fibra dietética $(\mathrm{g} /$ l00g m.s.) } & \multicolumn{3}{|c|}{ Índice glicémico** } \\
\hline & Total & Insoluble & Soluble & Normal & Diabético \\
\hline Name & 11 & 8 & 3 & $4 \mid$ & 33 \\
\hline Camote & 7 & 3 & 4 & 48 & 48 \\
\hline Yuca & 3 & 2 & 1 & 53 & 52 \\
\hline Nampí & 12 & 8 & 4 & 46 & 46 \\
\hline
\end{tabular}

*Tecson, 2007

**El control de los ejemplos fue el pan blanco. 
a una medición de la absorción de la glucosa en el organismo, y de los datos del estudio, se muestra que resulta ligeramente diferente para personas con diabetes en comparación con las personas que no padecen esta enfermedad. De manera general, se observa que para el ñame y el ñampi, que son los productos que contienen mayor cantidad de fibra total, y se obtuvo una respuesta con un menor valor de índice glicémico, reportado tanto para pacientes diabéticos como sin la enfermedad. Al comparar el contenido de fibra insoluble de las cuatro raíces analizadas (Cuadro 2), se observa que el contenido de fibra es mayor para el ñampí y el ñame, mientras que el camote y la yuca contienen cantidades menores.

En relación al contenido de fibra soluble es similar para todos los productos. Otro aspecto interesante es que a menor contenido de fibra total, tal es el caso de la yuca y el camote, los valores de índice glicémico son mayores.

\section{Modificaciones, aplicaciones y tratamientos del almidón de diferentes raíces de origen tropical a escala industrial}

\section{Modificación del almidón y el índice glicémico}

De las fracciones del almidón, la amilosa se absorbe mucho más lentamente que la amilopectina, debido a que las proporciones de estos dos polímeros pueden tener un efecto en el rango de digestión y por lo tanto en la absorción (Chiasson, 2000). Por esta razón, la ciencia busca modificar en los almidones la relación del contenido de amilosa y amilopectina, de forma tal que tengan más amilosa, para así buscar consecuentemente la disminución potencial del valor del índice glicémico. Con este propósito, Niba (2003) realizó un estudio con harinas de maíz, papa, malanga y ñame, en el cual se probaron varios tratamientos físicos para medir el efecto de ellos sobre el índice glicémico (medido por el método enzimático). Las harinas fueron sometidas a tratamientos tales como el autoclavado, microondas, a precocido y liofilizado. Estas muestras se almacenaron por un período de 10 días, a temperatura de congelación y ambiente y se estudió el contenido e almidón resistente (AR), almidón lentamente digerible (ALD) y almidón total (AT). Se encontró, que de las harinas estudiadas la de malanga presenta el mayor contenido de AR $(8,16 \mathrm{~g} / 100)$ y que el efecto del autoclavado y del precocido aumentan el contenido de $A R$, mientras que el efecto del microondas lo disminuye en comparación con el almidón nativo. El almacenamiento a temperatura ambiente también demostró tener un efecto sobre el contenido del AR reduciéndolo. La información obtenida en este estudio es importante para el desarrollo y almacenamiento de alimentos con el fin de modificar el contenido de almidón resistente para beneficio en la salud.

\section{Componentes bioactivos}

Muchos alimentos de consumo común contienen componentes bioactivos fisiológicamente beneficiosos como antioxidantes, carotenoides, fenoles, alcaloides y otros fitoquímicos. Dichos componentes activos se han estudiado con la finalidad de prevenir numerosas enfermedades, como cáncer y problemas cardíacos. También se han asociado con la disminución del envejecimiento y mejoras en la salud en general (Niba, 2003).

La familia del ñame (Dioscorea), por ejemplo, contiene fitoestrógenos, los cuales también han demostrado beneficios fisiológicos (Araujo et al., 2004). Algunas variedades de camote han mostrado un potencial antidiabético (Osundahusi, 2003). Tecson (2007) reporta en su estudio que las raíces de origen tropical tales como camote, yuca, ñame y ñampí, contienen potencial antioxidante igual o superior al control butilhidroxianisol (BHA) y $\alpha$-tocoferol, por lo que, al igual que lo estudiado por Niba (2003).

En el caso del ñampí (Colocasia a esculenta), no se han estudiado ampliamente los compuestos bioactivos, sin embargo señala el autor que se han encontrado antocianinas en el ñampi producido en Nueva Zelanda. Hedges (2006), menciona en esta recopilación que la información existente al respecto está muy escueta, por lo tanto, se podría considerar que en las raíces y los tubérculos que aún no hay información suficiente para considerar su valor como productos funcionales bioactivos.

\section{Fermentación y bioprocesamiento}

La fermentación del almidón de las raíces de origen tropical estudiadas se realiza muy comúnmente de forma natural, donde el almidón es el medio para el crecimiento de las bacterias. Este tipo de fermentación se caracteriza por el crecimiento predominante de bacterias ácido lácticas, confirmado por la rápida y drástica disminución del pH. Las bacterias ácido lácticas aumentan durante los cinco primeros días 
de fermentación y la producción de ácido láctico continúa aún hasta el día 20 (Brabet et al. 1999). La yuca y el ñame fermentados son ejemplos en varias partes de África y la fermentación afecta típicamente a bacterias y levaduras, facilitando así la preservación y el almacenamiento. En este proceso, disminuyen los taninos debido a la fermentación (Niba, 2003).

La fermentación aumenta de forma notable la calidad nutricional en los productos alimentarios, como, por ejemplo, el contenido de proteína en algunos granos que han sido enriquecidos por fermentación. Además, la fermentación resulta en la modificación de almidones provenientes de almidones resistentes, los cuales se asocian con la protección del cáncer de colon y enfermedades gastrointestinales. La fermentación también se ha estudiado como una vía para la elaboración de productos "sin gluten", de tal forma que se utilice en la industria del pan (pan de yuca y pan de bono); este tipo de fermentación se ha estudiado en la yuca (Brabet et al., 1999). En el estudio realizado por Vargas, et al (20I2), se encontró que el almidón agrio tiene un contenido en almidón resistente $A R$, similar al de las pastas de trigo duro, con lo que se establece la posibilidad de utilizar esta materia prima en el desarrollo de alimentos con propiedades funcionales.

\section{Almidón de yuca: un ingrediente con propiedades funcionales}

\section{Disminución de la absorción de grasa en frituras}

Según Martelli et al. (2008), es posible que la adición de algunos polisacáridos sirva de barrera para la grasa en alimentos fritos. En su estudio, se analizó "nuggets" de pollo a los cuales se les agregó almidón de yuca, antes del empanizado, con el objetivo de verificar si se lograba una disminución en la absorción de grasa del producto al freírse. En el estudio se obtuvo una disminución significativa del contenido de grasa del $16 \%$ con respecto al control.

En otro estudio, realizado por Osundahusi et al. (2003), se analizaron las propiedades funcionales de dos variedades de camote, encontrándose una baja absorción de aceite en ambas y atribuyéndose esta característica a la baja cantidad de proteína contenida en este almidón.

El uso de almidones con baja absorción de aceite en los procesos de fritura sería de gran utilidad en la industria actual de comidas rápidas ya que podría proveer nuevas fuentes de materias primas que se adecuen más a los requerimientos técnicos para estos procesos (incluyendo la reducción de costos por una menor absorción de aceite) y adicionalmente será un factor de beneficio también para la salud de los consumidores.

\section{Almidón pregelatinizado para elaboración de pan y bebidas energéticas}

Se ha estudiado los almidones fermentados de raíces como la yuca para utilizarlos como ingredientes en la elaboración de pan, pudines y otros productos que requieren de rápida miscibilidad con las otras materias primas. Este almidón que tiene una capacidad diferente, ya que expande cuando es sometido al calor y de alguna manera, logra realizar el trabajo del gluten, que se encuentra en el trigo, al cual muchas personas presentan intolerancia. El almidón de yuca se utiliza de esta forma en India, Brasil y Colombia, y gracias a este ingrediente se evita que la masa se "quiebre" y se obtiene un producto muy similar al pan de trigo (Prenkumar et al., 2008).

La obtención de almidón pregelatinizado es otra manera de utilizar este producto, consiste en someter al almidón de yuca aun proceso de gelificación, seguida por un secado, obteniéndose un gránulo firme, cuyo tamaño finalmente se reduce mediante una especie de molienda que no deje el grano demasiado fino. En India, el almidón pregelatinizado fino se utiliza para elaborar una bebida energética instantánea con agua o leche caliente, destinada a los niños o personas que requieren alimentos altamente energéticos (Prenkumar et al., 2008).

\section{Discusion y conclusiones}

Con este estudio se pretende demostrar que las harinas y almidones raíces y tubérculos, pueden tener un mayor uso en la industria alimentaria. Se encontró que éstos productos tienen varias propiedades funcionales demostrando que el contenido de amilosa-amilopectina, así como viscosidad y contenido de fibra, afectan el proceso de digestibilidad del almidón, por lo cual su uso y aplicación en los alimentos podría diversificar la oferta de productos alimenticios y así ofrecer nuevos a poblaciones que requieren consumir alimentos de bajo índice glicémico. Podemos pensar por ejemplo, que se puede utilizar el almidón de alguna de estas raíces 
para espesar un alimento infantil para niños con diabetes, dado que el almidón ayuda a darle la consistencia deseada sin aumentar de manera sustancial el índice glicémico.

El valor nutricional de estas harinas y almidones es altamente energético y son fuente de carbohidratos, sin embargo, son escasos en proteína y bajos en grasa, por lo que se pueden usar para mejorar el contenido energético de ciertos alimentos, sin suministrar grasa extra, por lo que también pueden ser un ingrediente funcional. El desarrollo de concentrados de alimentos especiales para personas cuya alimentación en cuanto a volumen debe ser limitada, pero cuyo contenido energético puede ser alto es otra opción de uso.

La fermentación de los almidones de yuca, ñame, ñampí y camote es otra alternativa que podría mejorar su valor nutricional. Además, la utilización de almidones fermentados como sustitutos del gluten para la elaboración de panes también resulta beneficiosa para otro grupo de la población, los celiacos, que podrían consumir este tipo de pan sin problema. En el caso específico de estos almidones deben de ser combinados con otros productos para aumentar la textura y generar una miga adecuada, así como el color y el sabor característicos del pan, sin embargo es una opción que se debe estudiar.

Otra propiedad importante de estos almidones es su aplicación como una especie de "barrera" para evitar la absorción de grasa en frituras, así como evitar la pérdida de agua en este tipo de productos. Esta propiedad puede permitir obtener frituras con menor absorción de grasa, lo cual podría ayudar problemas a nivel de salud, muy comunes en la población actual.

Es necesario efectuar más estudios sobre las propiedades funcionales de estos almidones, especialmente aplicados a los alimentos y no de forma aislada. Sería importante estudiar casos clínicos para observar el comportamiento del índice glicémico de los alimentos en personas con diabetes, así como la absorción de grasa en frituras, con el fin de desarrollar productos novedosos que contengan estos almidones y beneficiar así la salud de la población aprovechando sus propiedades funcionales. La innovación de alimentos ligada a alimentos que cuiden la salud, podría ser una fuente de uso de los tubérculos y las raíces en lo que corresponde al uso de materias primas locales.

\section{Bibliografía}

Araujo, C., Rincón, A. \& Padilla, F. (2004). Caracterización del almidón nativo de Dioscorea bulbifera L. Archivos Latinoamericanos de Nutrición 54 (2): 24I-245. Obtenido desde: http://www.scielo.org.ve/scielo.php?pid=S0004062220040002000 I 6\&script=sci_arttext

Brabet, C., Chuzel, G., Dufour, D., Raimbault, M. \& Giraud, J. (1999). Improving cassava sour starch quality in Colombia. International Meeting on Cassava Flour and Starch (p. 24I246). Cali: CIAT.

Chiasson, J. (2000). Glycemic index of foods and glycemic control in type I diabetes. Current opinion in endocrinology and diabetes $7(1): 25-30$.

Hedges, L.; Lister, C. 2006. Crop \& Food Research Confidential Report No. 1569. A report prepared for Horticulture New Zealand.(p. 23-26).New Zealand. Crop Food Research.

Karam, L., Ferrero, C., Martino, M., Zaritzky, N. \& Grossmann, M. (2006). Thermal, microstructural and textural characterization of gelatinized corn, cassava and yam starch blends. International Journal of Food Science and Technology 4I: 805-8I2.

Martelli, M.R., Carvalho, R.A., Sobral, P.J.A. \& Santos, J.S. (2008). Reduction of oil uptake in deep fat fried chicken nuggets using edible coatings based on cassava starch and methylcellulose. Italian J. of Food Science 20: | | | - | | 8 .

Mataix, J. (2007). Nutrición y Alimentación Humana: Nutrientes y alimentos. Vol. I. p. 305-307. Madrid: Ergon.

Moorthy, S. (2004). Starch in food: structure, function and applications. Cambridge: Publishing Limited Woodhead.

Niba, L. (2003). The relevance of biotechnology in the development of functional foods for improved nutritional and health quality in developing countries. African Journal of Biotechnology 2(12): 631-635.

Onitilo, M., Sanni, L., Oyewole, O. \& Maziya-Dixon, B. (2007). Physicochemical and functional properties of sour starches from starches from different cassava varieties. International Journal of Food Properties 10(3): 607-620.

Osundahusi, O., Fagbemi, T., Kesselman, E. \& Shimoni, E. (2003). Comparison of the physicochemical properties and pasting characteristics of flour and starch from red and white sweet potato cultivars. Journal of Agricultural and Food Chemistry 51: 2232-2236.

Prenkumar T., Padmaja, G., Moorthy, S., Nanda, S., Mathew, G. \& Balagopalan, C. (2000). New cassava products of future potential in India. En: Howeler, R.H. \& Tan, S.L. (eds). Cassava's Potential in Asia in the 21 st century: Present situation and future research and development needs. Proc. $6^{\text {th }}$ Regional Workshop, 21-25 febrero (pp. 564-577). Ho Chi Minh: CIAT.

Rached, L., Vizcarrondo, C., Rincón, A. \& Padilla, F. (2006). Evaluación de harinas y almidones de mapuey (Dioscorea trifida), variedades blanco y morado. Archivos Latinoamericanos de Nutrición 56(4). Obtenido desde: http://www.scielo. org.ve/scielo.php?pid=S0004062220060004000 I 0\&script= sci_arttext 
Riley, C., Wheatley, A. \& Asemota, H. (2006). Physicochemical characterization of starches from jamaican yams (Dioscorea spp.): Potential for pharmaceutical exploitations. European Journal of Scientific Research I5 (2): 207-219.

Robertson, J. (1988). Physicochemical characteristics of food and the digestion of starch and dietary fiber during gut transit. Proceedings of the Nutrition Society 47 (2): I43- 152.

Tecson, E. (2007). Development of functional foods in the Philippines. Food Science and Technology Research 13 (3) |79-| 86.

Ting-jang, L., Jheng-hua, L., Jia-ci, C. \& Yung-ho, C. (2008). Characteristics of ñampí (Colocasia esculenta) starches planted in different seasons and their relations to the molecular structure of starch. Journal of Agricultural and Food Chemistry 56(6): 2208-22I5.

Treche, S. 1996. Tropical root and tuber crops as human staple wood. Conferencia. I Congreso Latinoamericano de raíces tropicales. (7-10 Octubre, San Pedro - SP - Brazil).

Vargas, P.; Araya, Y.; López, R.; Bonilla, R. (2012). Características de calidad y digestibilidad in vitro del almidón agrio de yuca (Manihot esculenta) producido en Costa Rica. Revista Venezolana de Ciencia y Tecnología de Alimentos. 3 ( I):00 I-0 I 3 . 